\title{
DECISÃO DE COMPRA DO CONSUMIDOR NA ÓTICA DO NEUROMARKETING E NA ERA DA CONECTIVIDADE CONTÍNUA
}

\author{
Consumer purchase decision under the neuromarketing point of view and in \\ the era of continuous connectivity
}

\author{
Davi Manoel Krube Aquino'; Rodrigo André Cechett ${ }^{2}$
}

\begin{abstract}
${ }^{1}$ Pós-graduando em Marketing, Comunicação e Branding na URI Erechim. Graduado em Engenharia Civil. Empreendedor.E-mail: davimka@gmail.com

${ }^{2}$ Graduado em Administração de Empresas. Mestre em Administração. Especialista em Marketing. Empreendedor. Assessor de Marketing e Professor na URI Erechim.E-mail: cechett@uricer.edu.br
\end{abstract}

Data do recebimento: 28/05/2021 - Data do aceite: 07/06/2021

RESUMO: A conectividade das comunicações e interações está cada vez mais ininterrupta nos moldes da sociedade atual, onde a tomada de decisão de compra dos consumidores recebe grande influência de diversificadas estratégias de marketing, baseadas, principalmente, nos estudos de neuromarketing. O objetivo deste artigo é trazer um entendimento amplificado dos principais fatores que influenciam o consumidor na tomada de decisão de compra, buscando entender com maior clareza seu comportamento e os processos envolvidos nas decisões de compra. Para cumprir com este objetivo, foi conduzida uma pesquisa exploratória a partir da coleta de informações em referências bibliográficas.

Palavras-chave: Comportamento do consumidor. Consumidor. Decisão de compra. Marketing. Neuromarketing.

ABSTRACT: The connectivity of communications and interactions is increasingly uninterrupted in the role similar to today's society, where the decision making to purchase by consumers is greatly influenced by diversified marketing strategies, based mainly on neuromarketing studies. The objective of this article is to bring an amplified understanding of the main factors that influence the consumer in making a purchase decision, seeking to understand more clearly his behavior and the processes involved in the purchase decisions. 
To fulfill this objective, an exploratory research was conducted based on the collection of information in bibliographic references.

KEYWORDS: Consumer behavior. Consumer. Buying decision. Marketing. Neuromarketing.

\section{Introdução}

A ideia central deste artigo é apresentar um entendimento amplificado de situações específicas envolvendo os hábitos e costumes dos consumidores no processo de compra, buscando uma percepção mais clara desses comportamentos, a fim de obter informações úteis para utilização e estruturação de estratégias de vendas no mundo dos negócios.

Com a finalidade de obtenção de um embasamento teórico coeso, é fundamental apontar a importância da contribuição dos estudos da neurociência para o desenvolvimento do artigo. É por meio desses estudos que se obtêm uma perspectiva segura para analisar como o consumidor toma suas decisões na hora da compra.

Vivemos em uma era de conectividade contínua, um mundo que a cada dia que passa está familiarizando-se e adaptando-se ainda mais nessa atmosfera da conectividade contínua, resumidamente, um mundo on-line. Este cenário de conexão está influenciando todas as camadas da nossa sociedade, desde a forma de pensar até as tomadas de decisões, e por conta disso, será indispensável analisar as induções e influências desse mundo on-line na tomada de decisão de compra por parte dos consumidores.

O neuromarketing se apresenta como a arma mais poderosa na elaboração de estratégias de publicidade os estudos resultantes da neurociência fornecem dados e informações valiosas para aplicações em atividades de marketing. A maneira como cada indivíduo percebe o mundo ao seu redor pode ser muito diferente, mas estamos todos atrelados aos mesmos padrões biológicos de funcionamento, o que permite, em linhas gerais e no que diz respeito às estratégias de marketing, definir quais ações tomar em cada diferente tipo de comportamento do consumidor.

Quanto à classificação da pesquisa, para a estruturação deste artigo, foi feita uma pesquisa exploratória, buscando um maior aprofundamento e familiarização ao tema. Levando em consideração que os estudos de neuromarketing e suas influências no que tange o comportamento do consumidor são vistos como conhecimentos relativamente novos, principalmente no Brasil, a pesquisa se propõe a explorar estes assuntos em busca de mais informações sobre o comportamento do consumidor na hora da compra, mais especificamente, na tomada de decisão de compra.

\section{Neuromarketing e o consumidor}

O maior interesse das empresas sempre foi, obviamente, vender seus produtos e serviços, focando boa parte dos seus esforços na produção de resultados, ou seja, gerar receita a qualquer custo. Mas nem tudo é somente fechar vendas questões mais importantes devem ser consideradas. É preciso pensar em todo o processo que envolve uma venda. É necessário entender a motivação da ação de compra por parte consumidor, buscar o máximo de dados envolvendo toda a jornada do consumidor.

Existe uma grande quantidade de informações transmitidas por diferentes canais de 
comunicação quando a questão é o consumo de produtos, recursos, serviços e tecnologias. O que ocorre é o surgimento de muita disputa pela atenção do consumidor, em um cenário onde comprar é algo totalmente natural no cotidiano da sociedade (REDIVO; GOUVEIA, 2018).

Uma sociedade tão dinâmica, com propensão à mudança de opinião tão constante e exposta à tanta informação de rápido acesso, traz o desafio, para as empresas, de um acompanhamento além da oferta de produtos e serviços de qualidade. Isso quer dizer que a necessidade de observação das mudanças dos consumidores deve ser ressaltada, juntamente com previsão de tendências dos mesmos para atingir a satisfação dos clientes. Neste contexto, é importante frisar que a maioria das ferramentas e mecanismos em uso, por grande parte das empresas para descobrir o que o consumidor pensa, apresentam-se defasadas e com várias limitações (LINDSTROM, 2008, apud REDIVO; GOUVEIA, 2018).

Em uma era de grandes avanços tecnológicos e de pesquisas no entendimento de mercado, ocorreu o surgimento da necessidade da obtenção de uma compreensão mais clara a respeito do comportamento dos consumidores. Despertando o interesse em relevantes questões voltadas às atitudes dos consumidores, como por exemplo: o que ativa um pensamento, uma emoção ou ação que faça com que eles decidam comprar ou simplesmente reconheçam uma marca, serviço ou produto? Todas essas são questões que podem ser contempladas através do neuromarketing (REDIVO; GOUVEIA, 2018).

Segundo Lindstrom (2009, p. 15), neuromarketing é uma ferramenta que busca a compreensão das emoções, pensamentos e desejos do subconsciente que acabam impulsionando as tomadas de decisões de compra. E ainda de acordo com Bercea (2013, p. 2), dentro da neurociência, o neuromarketing é um ramo de pesquisa que procura estudar de modo aprofundado os processos inconscientes, resultando na compreensão das expectativas e preferências do consumidor (apud COHEN; LIMA; SCHULZ, 2017, p. 4).

\section{Áreas do cérebro}

Para Paul MacLean (1970), o cérebro humano distingue-se em três diferentes áreas: a Reptiliano - exercendo a responsabilidade nas funções instintivas básicas de sobrevivência, de alimentação, hidratação e o sexo, o Límbico - responsável por todas as emoções, reações afetivas, instinto maternal, medos e agressividade, e o Neocortex - localizado na região superior do cérebro, área responsável por toda a nossa capacidade de racionalizar, de pensar e decidir. Essas três partes do cérebro são chamadas por MacLean de cérebro trino, conforme Figura 1 (apud BOARINI; FAGUNDES, 2017).

Segundo Klaric (2018), o pesquisador Paul MacLean obteve sucesso em seus estudos e pesquisas na área da neurociência ao apresentar a sua teoria da existência de três cérebros em apenas um. Embora seja questionada, o desenvolvimento desta teoria está demonstrando ser muito efetiva nas explicações e delimitações de aspecto importantes e determinantes do comportamento humano (apud DE HOLANDA FURTADO; FARIAS; DE SOUSA JÚNIOR, 2020).

De acordo com Braidot (2011), estes três níveis do cérebro, sobrepostos de forma progressiva, tem seu funcionamento de forma conectada e interligada, possuindo características específicas, e sendo o resultado de milhões de anos em todo o percurso da evolução. E segundo Peruzzo (2015), mesmo com a plasticidade e a possibilidade das funções cerebrais acontecerem de maneira simultânea, embora existam críticos e céticos, é evidente a diferença de maior atividade cerebral de uma área para outra durante o envio 
de comandos de decisão em processos impulsivos, emocionais e racionais. Deste modo, é oportuno o conhecimento e a evolução de teorias que possuem ligação com a lógica dos três cérebros (apud DE HOLANDA FURTADO; FARIAS; DE SOUSA JÚNIOR, 2020).

Figura 1 - $O$ cérebro trino de Paul MacLean

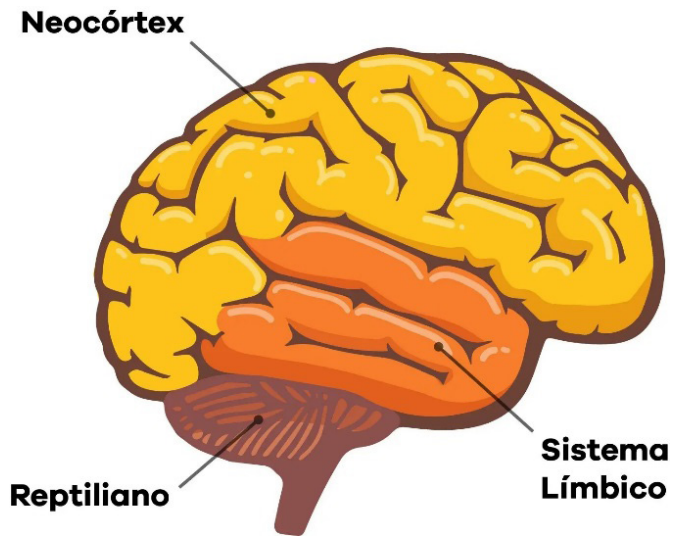

Fonte: ASSOWEB (2020)

Para Army (2009), compreender o funcionamento do cérebro nos leva a uma análise multidisciplinar, visto que são incluídos os aspectos biológicos em nível molecular, até as expressões cognitivas, passando pelos neurônios, hormônios, coluna, a percepção visual e dos demais sentidos do corpo humano, partindo do córtex até as mais altas complexidades do sistema nervoso (apud BOARINI; FAGUNDES, 2017).

\section{Comportamento do consumidor}

Pode-se entender comportamento do consumidor como o estudo dos conjuntos de processos em que indivíduos ou grupos de indivíduos se envolvem em ações de seleção, compra, uso ou descarte de serviços, produtos, ideias ou experiências que satisfaçam suas necessidades e desejos (SOLOMON, 2011, apud DOS SANTOS et al., 2020).
O foco na compreensão destes fatores é algo que deve ser priorizado, pois a importância desse entendimento vai além de simplesmente conhecer as razões da aquisição de um determinado produto ao invés de outros produtos. Perceber isso é imprescindível para conquistar clientes e mantê-los fiéis. E para quem ambiciona possuir uma empresa de sucesso necessita conhecer com profundidade seus clientes e estudá-los com bastantes detalhes. Visto que os padrões comportamentais estão em constante mudança, e conforme o tempo passa é preciso entender as novas condutas dos clientes, para que o melhor aproveitamento de oportunidades seja maximizado (DOS SANTOS et al., 2020).

A ciência aliada ao marketing com embasamento nos comportamentos dos consumidores, formam um conjunto, que de acordo com a teoria behaviorista da aprendizagem produz um diagnóstico interessante, por parte dos psicólogos, onde é possível afirmar que os processos de aprendizagem do ser humano ocorrem como reação aos eventos externos. A mente humana recebe estímulos com aquilo que chama mais atenção da perspectiva dos aspectos observáveis, sendo basicamente estímulos de entrada e saída, em que os estímulos de entrada são provocados por eventos externos e os estímulos de saída são as reações resultantes dos estímulos de entrada (SPIGUEL; BAGLI, 2013).

Um aspecto muito relevante a ser considerado no comportamento do consumidor é o estado emocional do indivíduo, pois este é fortemente guiado por afetos conscientes e inconscientes, o que pode produzir estados de insegurança ou segurança, dependendo do ambiente e situações em que esteja exposto (OLIVEIRA, 2007, apud MORIGONI; BAPTISTA; PINHEIRO, 2017).

Na hora de realizar pesquisas de consumo é preciso observar que aspectos biológicos exercem grande influência no comporta- 
mento humano. É muito complicado para o consumidor, em diversos momentos, descrever os motivos reais de comprar um produto e não um outro. Em boa parte das vezes, a vontade surge de forma puramente instintiva (REDIVO; GOUVEIA, 2018).

\section{A jornada de comportamento e atitude do consumidor}

Para entender o caminho do consumidor até uma determinada tomada de decisão, é preciso perceber como ele se comporta em diferentes situações, ou em que situação se encontra em um determinado instante. Não se deve pensar no consumidor como uma variável simples e única, e sim, como integrante fundamental de uma complexa equação social, cultural e econômica. Significa dizer que de forma quase imperceptível ele já está dentro de uma jornada de compra, pelo simples fato de estar inserido em uma atmosfera publicitária altamente dinâmica, seja nas interações físicas ou virtuais.

O estudo envolvendo comportamento do consumidor é visto como interdisciplinar, baseando-se em conceitos e teorias sobre as pessoas, sendo estes estudos desenvolvidos por cientistas nas mais diversas disciplinas, além da psicologia, sociologia, antropologia cultural, psicologia social e economia. (SCHIFFMAN; KANUK, 2000, apud COLAFERRO, 2014).

Figura 2 - O modelo simples de tomada de decisão

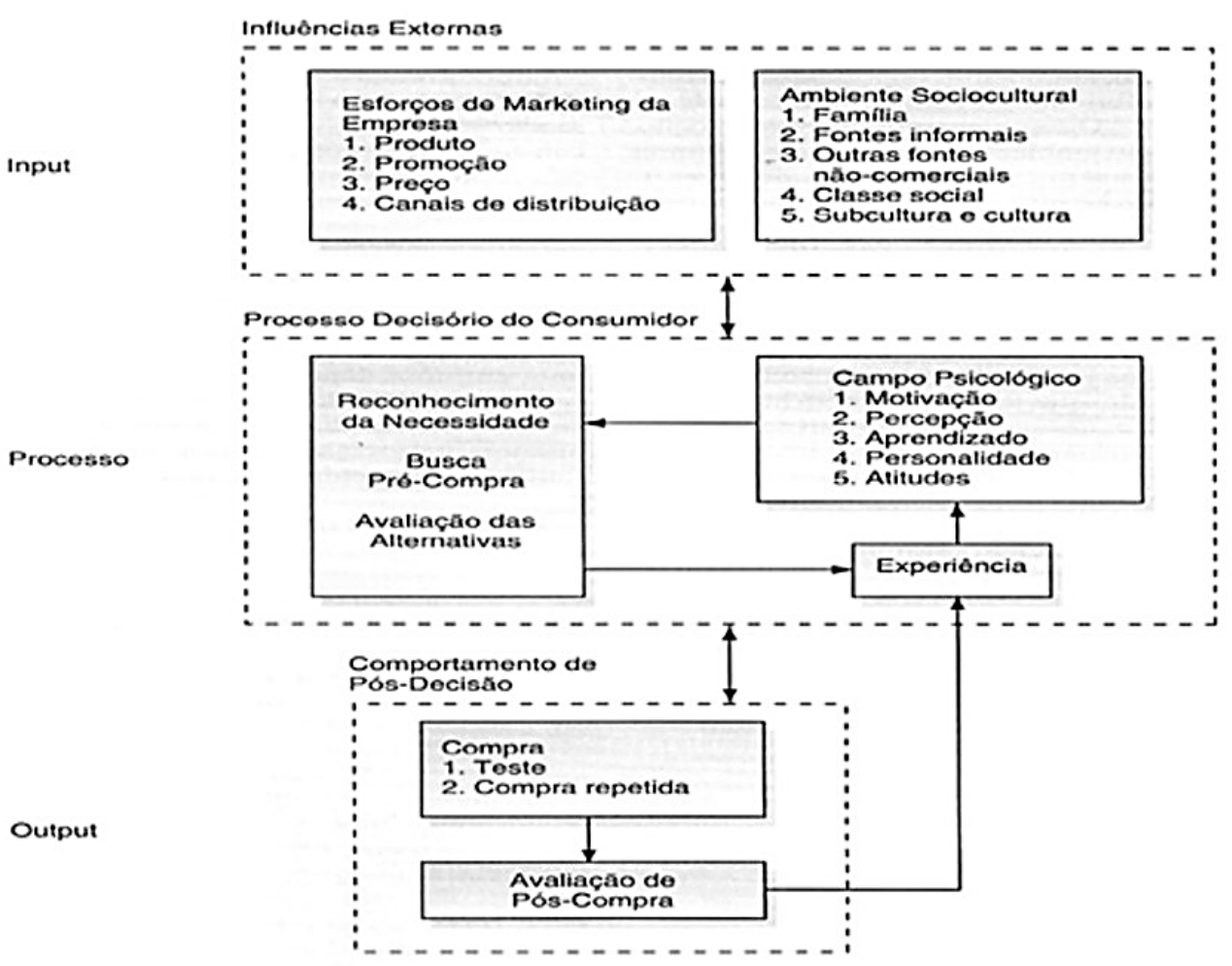

Fonte: (SCHIFFMAN; KANUK (1997, p.400), apud COLAFERRO (2014). 
De acordo com os autores Schiffman e Kanuk (2000), após investigação de um modelo de tomada de decisão do consumidor, determinaram que este modelo une conceitos psicológicos, culturais e sociais em uma estrutura de trabalho de fácil compreensão. O modelo em questão apresenta três fases, com algumas variáveis - a fase input, com variáveis de influências externas do ambiente mercadológico ou não; a fase de processo que inclui as variáveis de influências do campo psicológico do consumidor; e a fase de output, cujas variáveis envolvem o comportamento pós-decisão, como as experiências anteriores com o produto. Conforme Figura 2. (apud COLAFERRO, 2014).

Conforme as afirmações de D'alama (2018), a jornada de compra é entendida como o percurso pelo qual um cliente em potencial passa. As etapas dessa jornada são: aprendizado e descoberta, reconhecimento do problema, consideração da solução e a decisão de compra (apud SANTOS, 2019).

\section{Funil de vendas}

Para Hormann (2018), funil de vendas é visto como o processo de condução e acompanhamento do cliente logo após o momento que ele conhece a marca e então opta pelo fechamento da venda. E de acordo com MZ3 (2018), as etapas do funil estão diretamente ligadas com as fases da jornada de compra. Em primeiro lugar, é preciso atrair os visitantes e transformá-los em leads. Logo em seguida, com a captação de leads realizada, deve-se apresentar as oportunidades que eles terão ao optarem por seu serviço ou produto. Por fim, o objetivo é convertê-los em clientes, finalizando a compra. A divisão das etapas do funil é feita em três etapas: topo do funil, meio do funil e o fundo do funil. A representação do funil de vendas é normalmente apresentada como uma pirâmide invertida (apud SANTOS, 2019).

A Figura 3 mostra a representação do funil de vendas e da jornada de compra para clientes em potencial ao visitarem um determinado site de alguma empresa, cujo objetivo é oferecer algum produto e/ou serviço, conforme apresentado na Figura 3.

Segundo Marques e Levi (2020), com a finalidade de atingir os objetivos das empresas em suas metas de vendas, na virada do século XIX para o século XX, surgiu o modelo AIDA, explicando o comportamento do consumidor e suas motivações para escolher uma determinada marca ou produto, ajudando os vendedores em seus posicionamentos

Figura 3 - Funil de vendas e jornada de compra

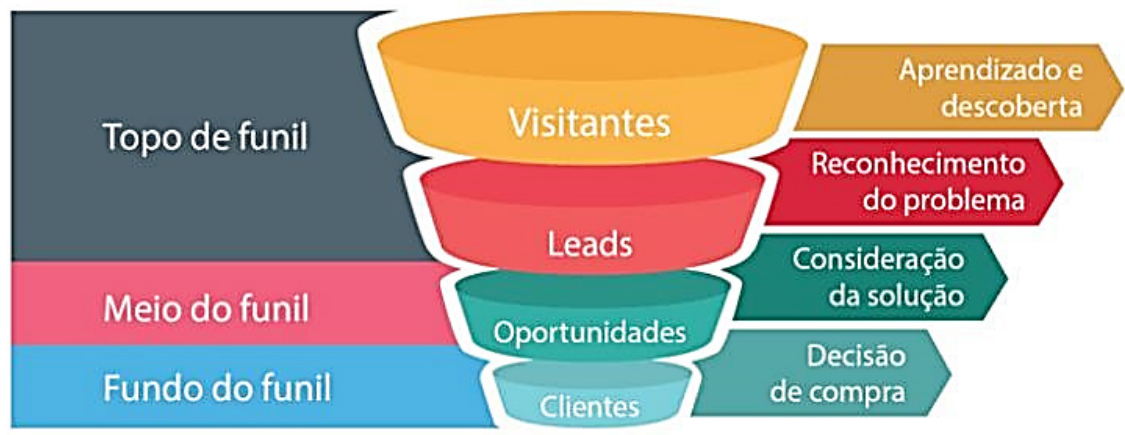

Fonte: ASSOWEB (2020) 
e ações. A AIDA é representada por quatro conceitos principais, sendo eles: atenção, interesse, desejo e ação. Com a evolução da internet, este modelo evoluiu a ponto de se tornar uma metodologia, com o suporte e apoio dos estudos científicos, sendo então batizada de "funil de vendas".

\section{Intenção e decisão de compra}

$\mathrm{Na}$ Teoria Motivacional de Freud as pessoas desconhecem seus próprios desejos. Desta maneira, é necessário enxergar a consciência aprisionada no inconsciente, definindo esta como a real fonte dos desejos de cada indivíduo, assim como o seu comportamento. É justamente nessa área que estão contidas as emoções, as imagens, os cheiros, o aprendizado e tantas outras coisas, tudo isso contribuindo diretamente para uma determinada ação. A relação entre o inconsciente com o consciente resulta na criação das diversas experiências de um indivíduo, estruturando suas opiniões e decisões (KOTLER; KELLER, 2006, apud VORPAGEL, 2017).

Segundo Cavaco (2010), Pradeep (2012) e Lindstrom (2008), no marketing são utilizados apenas dois dos cinco sentidos do corpo humano, sendo eles visão e audição. Ainda de acordo com Lindstrom (2008), as empresas deveriam ter como meta a criação de sinergia entre os cinco sentidos, pois deixar de explorar todos os sentidos e utilizar apenas dois, ocasiona a perda de ótimas oportunidades de reconhecimento de marca e de venda de produtos e serviços (apud REDIVO; GOUVEIA, 2018).

De acordo com uma pesquisa feita pela NeuroFocus, agência de estudos voltados ao neuromarketing, dirigida por Pradeep (2012), aponta que $95 \%$ das decisões de compra tomadas por consumidores são decididas em nível subconsciente, sendo que a tomada de decisão pode ser acionada por qualquer um dos cinco sentidos do corpo humano, seja pela audição, visão, tato, olfato ou paladar (apud REDIVO; GOUVEIA, 2018).

A decisão de compra por parte do consumidor ocorre após o indivíduo ter formado preferências entre marcas dentro do que pode ser escolhido. A partir daí pode surgir a intenção de compra para efetivar a aquisição da marca preferida. Contudo, existem dois fatores que podem interferir entre a intenção e a decisão da compra. O primeiro fator a ser evidenciado diz respeito às atitudes dos outros. E o segundo fator a ser considerado diz respeito às situações imprevistas (KOTLER, 1998, apud GIARETA, 2011).

Lindstrom (2016) descreve a famosa pesquisa feita no ano de 1975 com os refrigerantes Pepsi e Coca-Cola. Essa pesquisa foi realizada "às cegas", e o objetivo era descobrir qual dos dois sabores era mais apreciado pelo público. Os resultados surpreenderam mesmo com a Pepsi possuindo um market share menor que a concorrente, mais de $50 \%$ da amostra preferiu a marca da fabricante. Em 2003, uma nova pesquisa foi realizada pelo Dr. Montagne, da faculdade Baylor de Medicina, Texas. Nessa pesquisa, 67 pessoas foram submetidas ao mesmo experimento, utilizando o fMRI (Imagem de Ressonância Magnética Funcional), e os resultados foram fiéis ao primeiro experimento (1975), onde ocasionou o estímulo do putâmen ventral, responsável por identificar os sabores mais apreciados. Ainda, segundo Lindstrom (2016), em uma segunda etapa do experimento, agora com os participantes sabendo qual a marca das bebidas degustadas, os resultados mudaram consideravelmente, resultando em $75 \%$ de preferência para a marca Coca-Cola. Isso mostrou que na batalha emoção-razão, venceu a razão, isso significa que a preferência por Coca-Cola veio de outros atributos, e não pelo sabor do produto (apud BOARINI; FAGUNDES, 2017).

De acordo com Blackwell, Miniard e Engel (2005), o processo para a tomada de 
decisão de compra começa no momento que o indivíduo percebe uma lacuna entre o seu estado atual e o estado almejado, sendo a diferença entre esses estados vista como a necessidade, que é ocasionada por estímulos externos ou internos. Contudo, apenas a presença da necessidade não produz o ato de compra, é fundamental que seja percebida como relevante (apud BARBOSA; MARTINS, 2018).

Os profissionais de marketing têm a tarefa de buscar ampliar o entendimento do que acontece dentro do consciente do comprador, desde a entrada do estímulo externo até a tomada de decisão de compra, já que certas características do indivíduo comprador e seus estágios de decisão resultam em certas decisões de compra (BARBOSA; MARTINS, 2018).

Existe uma integração dos consumidores com as novas tecnologias e ao vasto oceano de informações, o que os torna consumidores ativos. Deste modo, conforme o envolvimento com o processo de compra aumenta, os esforços dos consumidores são maiores para buscar mais informações que sustentem a tomada de decisão de compra (BEATTY; SMITH, 1987, apud BARBOSA; MARTINS, 2018).

As estratégias usadas pelos consumidores na hora de realizar a seleção das alternativas passíveis de escolha são representadas por regras de decisão. Podem ser regras puramente simplistas, exigindo pouco esforço e tempo, ou então podem ser regras mais elaboradas e sofisticadas, exigindo, neste caso, muito esforço e tempo de processamento dos indivíduos consumidores (CARO, 2010).

$\mathrm{O}$ relacionamento entre consumidores e empresas tem passado por grandes mudanças. A maneira como se relacionam está mais dinâmica e as redes sociais têm trazido muitas alterações nos hábitos de consumo, o que acaba causando o surgimento de um consumidor melhor informado e exigente (NASCIMENTO; JIMENEZ; CAMPOMAR, 2014).

Para reforçar esse raciocínio, de acordo com Kotler e Keller (2006), existe a afirmação de que o consumidor busca informações nas redes sociais para subsidiar a compra, e para complementar, segundo Edelman e Hirshberg (2006), os consumidores dão crédito e maior confiança para as opiniões formadas pelos amigos (apud NASCIMENTO; JIMENEZ; CAMPOMAR, 2014).

Existe um modelo de análise para estudar as atitudes dos consumidores em relação à intenção de usar serviços automatizados baseados em tecnologia. Este modelo criado por Badholkar, é chamado de Modelo de Influência Geral (Overall Affect Model), onde a fundamentação desse modelo está baseada na visão de um processo de influência na tomada de decisão de compra, em que consumidores estariam predispostos a formar expectativas de qualidade em relação aos serviços baseados em tecnologias (GARCIA, 2007).

Para Pinheiro et al., (2011), engana-se o profissional de marketing que concebe a decisão de compra como algo individual. Se a comunidade influencia a decisão de compra, um tipo específico de grupo social é um dos mais importantes influenciadores no processo de compra: a família. E segundo Schiffman e Kanuk, (2009), a família possui três funções básicas quando a abordagem se refere ao comportamento do consumidor: o apoio emocional, o bem estar econômico e um estilo adequado de vida da família (apud MENDES, 2013).

\section{Fatores influenciadores na tomada de decisão de compra}

De acordo com Kotler (1998), os fatores que exercem influência no processo de tomada de decisão de compra são os: fatores 
culturais, fatores sociais, fatores pessoais e fatores psicológicos (apud GIARETA, 2011).

A busca por uma melhor compreensão dos fatores influenciadores do comportamento de compra do consumidor possibilita uma visão detalhada da dinâmica da compra, criando assim possibilidades de interferência, como a utilização de estímulos de marketing que buscam causar resultados positivos no comportamento de compra, criando, assim, mais valor na percepção do cliente e também na satisfação com o produto (PINHEIRO, 2006, apud DOS SANTOS et al., 2020).

\section{Fator cultural}

Segundo Halat (2018), os valores culturais são derivados, em parte, das necessidades e desejos apresentados pelo consumidor, e determinam as suas preferências por serviços e produtos. Na ótica das organizações essas influências criam oportunidades de negócios (apud DOS SANTOS et al., 2020).

E para Kotler e Keller (2006), os fatores culturais são os que exercem a mais ampla e profunda influência sobre os indivíduos consumidores. E esses fatores encontram-se subdivididos em três: cultura, subcultura e classe social (apud GIARETA, 2011).

\section{Fator social}

São entendidos como fatores sociais, a família, os grupos de referência, papéis e posições sociais, ondem resultam em uma grande influência dentro de todos os processos do comportamento de compra dos indivíduos consumidores (GIARETA, 2011).

O homem por si só é um ser social, que convive em grupos, sendo que estes podem moldar o comportamento de consumo de todos os indivíduos que os compõe, e quanto mais elevada for a intimidade entre os integrantes dos grupos e quanto mais identificação existe entre seus membros, maior vai ser a influência exercida, destes grupos, sobre o comportamento do indivíduo (BARBOSA; MARTINS, 2018).

\section{Fator Pessoal}

De acordo com Giareta (2011), os fatores pessoais dizem respeito às características particulares de cada pessoa. Deste modo, os momentos e vivências pelas quais o indivíduo está passando, acabam por interferir nos seus hábitos e em suas decisões de consumo.

E segundo Kotler (1998), existem cinco elementos que compõem os fatores pessoais, sendo eles: idade e estágio do ciclo de vida, ocupação, condições econômicas, estilo de vida e personalidade (apud GIARETA, 2011).

\section{Fator psicológico}

Segundo De Souza (2018), os fatores psicológicos são baseados na utilização de lembranças da infância, da motivação e o desejo de possuir a sensação de realização. O que acaba exercendo uma relevante influência no comportamento do consumidor.

Já para Kotler (1998), são quatro os mais importantes fatores psicológicos que interferem e influenciam nos comportamentos dos consumidores, sendo eles a motivação, a percepção, a aprendizagem e as crenças e atitudes (apud GIARETA, 2011).

De acordo com Giareta (2011), para que o consumidor decida comprar é preciso que dentro de sua mente sejam desenvolvidos os estados de existência de uma determinada necessidade; a consciência desta necessidade; o conhecimento do objeto que pode satisfazê-la; o desejo de satisfazê-la e, finalmente, a decisão por um determinado produto.

\section{Fator biológico}

Para Redivo e Gouveia (2018), em muitos casos, o consumidor não sabe os reais moti- 
vos dos seus desejos de compra, se escolhe comprar um ou outro produto. Em diversas situações, essa vontade de comprar é apenas instintiva, evidenciando a herança do cérebro primitivo que passou por processos evolutivos e ganhou muitas outras funções.

Dos fatores biológicos que mais exercem influência no comportamento humano, os neurônios-espelhos se destacam. Esses neurônios são ativados quando o indivíduo realiza uma determinada ação ou apenas quando uma ação é observada. Lindstrom (2009), esclarece que esses neurônios-espelhos não são ativados ao observar qualquer ação e, sim, são ativados quando algum objeto é envolvido. Os neurônios-espelhos são responsáveis por motivar a compra. Por conta disso, as áreas do marketing e publicidade buscam criar uma identidade/atitude com seus produtos, fazendo o consumidor, por meio dos seus anúncios, desejar adquirir aquela imagem ou aquilo que ela transmite (SAMPAIO; et al., 2019).

Contudo, Lindstrom (2009), sinaliza que os neurônios-espelhos não atuam sozinhos. Existe uma ligação entre eles e a ação da dopamina (substância química cerebral relacionada ao prazer). Ele ressalta que para nós seres humanos, essa é uma das substâncias mais viciantes. Quando ocorre a decisão de compra, a dopamina enche o cérebro de prazer, trazendo as sensações de bem-estar (apud SAMPAIO; et al., 2019).

Ainda segundo Lindstrom (2009), o processo para decidir realizar uma compra demora menos que 2,5 segundos. Além disso, é um engano pensar que por ocorrer tão rapidamente, não exista uma motivação em suas escolhas. O cérebro cria "atalhos", que com grande rapidez realiza conexões inconscientes, resultando em ações. Os "atalhos" mencionados, são chamados de "marcadores somáticos", os quais reúnem as experiências anteriores vinculadas à re- compensa e punição, relacionando, desse modo, as experiências ou emoções com as reações (RODRIGUES; BACALTCHUK; OLIVEIRA, 2014).

\section{Conectividade contínua e a influência das mídias sociais}

De acordo com Passarelli (2020), a tecnologia digital está centralizada no modo de vida contemporâneo por meio da conectividade contínua, aprofundando o DNA disruptivo da revolução da Internet, agora no imbricamento da Internet das Coisas (IoT), Inteligência Artificial e Big Data. O interesse nos jovens e seu entorno está em evidência desde o início da segunda década do século XXI, dada a emergência de novos públicos e novos hábitos de consumo. Muitos estudos e pesquisas estão em desenvolvimento para desvendar os hábitos e anseios deste jovem, visto que nele está o futuro do nosso futuro.

Para Bruno (2020), a liderança dos usuários sobre as relações de produção e consumo, o compartilhamento de tecnologias entre a sociedade e indústria e, a virtualização de procedimentos que vinculam certas características de produtos de informação a produtos físicos, poderiam estar causando restrições nas estratégias voltadas à segmentação da informação e apresentando tendências monopolistas, implantando, desta forma, o princípio da conectividade contínua.

A era em que vivemos é uma era digital. O mais privilegiado nesse contexto todo é o consumidor, pois além de poder vislumbrar possibilidades novas de construir um relacionamento com empresas e pessoas das mais variadas localidades, recebe também a oportunidade de usufruir de novas possibilidades de compras, novas oportunidades de negócios, e principalmente rapidez para adquirir produtos e informações, pois os sis- 
temas que envolvem as dinâmicas da nossa sociedade estão ficando cada vez mais integrados e conectados (KOTLER, 2005, apud DAMASCENO, 2017).

\section{Considerações Finais}

Com o desenvolvimento deste artigo, foi possível concluir que o impacto dos estudos do neuromarketing, na compreensão do consumidor, são indispensáveis, em se tratando do atual cenário, em que as comunicações e interações sociais e econômicas estão mais intensas e complexas.

Concluiu-se, também, sobre como os fatores influenciadores nas decisões do consumidor são fundamentais para uma análise completa de cada perfil de consumidor, pois a comunicação de um produto e/ou serviço com um consumidor específico, necessaria- mente, se encaixa em um padrão que pode ser facilmente associado com qualquer um dos fatores, seja o fator cultural, social, psicológico ou pessoal. Dependendo de como uma oferta é feita, pode acionar diferentes gatilhos mentais no consumidor, fazendo com que ele tome uma decisão.

Não é sensato determinar um ou outro fator como o mais importante, pois dentro da complexidade e profundidade da mente humana, obter uma resposta completa e perfeita de qual foi o exato fator influenciador em uma determinada decisão, é uma tarefa incompleta. Entretanto é sensato dizer que a dinâmica destes fatores pode ser totalmente previsível nas aplicações estratégicas dentro do marketing, pois podem ser analisados, em conjunto ou separadamente, para diferentes ações, e os resultados destas ações podem ser mensurados e facilmente comparados.

\section{REFERÊNCIAS}

ASSOWEB. Neuromarketing: o que é e como se beneficiar dele. 2020. Disponível em: https:// www.assoweb.com.br/neuromarketing-o-que-e-e-como-se-beneficiar-dele/. Acesso em: 12 jun. 2021. BARBOSA, R. A. P.; MARTINS, A. V. S. Processo decisório de compra do consumidor frente às redes sociais: um estudo de caso. In: Congresso Latino-Americano de Varejo e Consumo - CLAV 2018. 2018, São Paulo. Anais [...]. São Paulo: Fundação Getúlio Vargas, 2018. Disponível em: http:// bibliotecadigital.fgv.br/ocs/index.php/clav/clav2018/schedConf/presentations. Acesso em: 10 fev. 2021

BRUNO, F. da S. A primeira revolução social da indústria e o princípio da conectividade contínua. Parcerias Estratégicas, v. 24, n. 48, p. 57-80, 2020.

BOARINI, D. M.; FAGUNDES, L. Despindo a lógica: a tecnologia revela as decisões de consumo a partir do uso do neuromarketing e do big data na propaganda e no branding. In: INTERCOM SOCIEDADE BRASILEIRA DE ESTUDOS INTERDISCIPLINARES DA COMUNICAÇÃO $40^{\circ}$ CONGRESSO BRASILEIRO DE CIÊNCIAS DA COMUNICAÇÃO - Curitiba - PR. 2017. p. 1-15. Curitiba, PR. Anais [...]. Curitiba: Universidade Positivo- UP - CURITIBA - PR, 2017.

CARO, A. Comportamento do consumidor e a compra on-line: uma análise multicultural. 2010. Tese (Doutorado em Administração) - Faculdade de Economia, Administração e Contabilidade, Universidade de São Paulo, São Paulo, 2010.

COLAFERRO, C. A.; CRESCITELLI, E. A Contribuição do Neuromarketing para o Estudo do Comportamento do Consumidor. BBR-Brazilian Business Review, v. 11, n. 3, p. 130-153, 2014.

COHEN, E. D.; LIMA, G. G.; SCHULZ, P. A. B. Neuromarketing: uma nova disciplina acadêmica? Marketing \& Tourism Review, v. 2, n. 2, p. 1-31, 2017 
DAMASCENO, M. R. A influência das mídias digitais no processo de decisão de compra: um estudo de caso com estudantes da graduação de administração da UFRN. 2017. Trabalho de Conclusão de Curso. Universidade Federal do Rio Grande do Norte.

FURTADO, I. R. R. de H; FARIAS, M. L.; SOUSA JÚNIOR, J.H. de. A utilização do neuromarketing na formulação de estratégias de vendas mais eficazes. Revista GESTO: Revista de Gestão Estratégica de Organizações, v. 8, n. 2, p. 56-70, 2020.

DE SOUZA, B. H.; POHL, R. Estratégias do Neuromarketing - Conhecendo suas técnicas de persuasão Strategies of Neuromarketing-Knowing their techniques of persuasion. Revista Brasileira de Pesquisas de Marketing, Opinião e Mídia, v. 11, n. 2, p. 236-244, 2018.

DOS SANTOS, F. A. M. R.; ALVES, G. J.; DE BRITO, L. A.; RIBEIRO, P. E. Neuromarketing: A Ciência por Trás do Consumo. Revista Contribuciones a las Ciencias Sociales, março, 2020.

GARCIA, G. M. Comportamento do consumidor virtual: a influência das características pessoais na intenção de compra. 2007. 53 f. Trabalho de Conclusão de Curso (Bacharel em Administração) Departamento de Ciências da Administração da Faculdade Federal do Rio Grande do Sul, Porto Alegre, 2007.

GIARETA, L. F. O comportamento do consumidor no processo de decisão de compra. In: III Encontro Científico e III Simpósio de Educaçăo. 2011, Lins. Anais [...]. Lins, SP: Unisalesiano, 2011.

MARQUES, H.; LEVI, R. Funil de vendas: um jeito fácil para você realizar bons negócios. Editora Senac São Paulo, 2020.

MENDES, E. R. Você compra pensando neles e eles nem sabem: um estudo das influências indiretas no processo de compra. Dissertação. 2003. f. 43 (Mestrado Profissional em Administração) - Fundação Cultural Dr. Pedro Leopoldo. Minas Gerais, 2013.

MENEGATTI, M. S. et al. Decisão de compras pela internet: uma análise a partir do tempo de utilização de mídias sociais e da interatividade com a marca. Revista Brasileira de Marketing, v. 16, n. 1, p. 41-54, 2017.

MORIGONI, M. M.; BAPTISTA, J. A. de A.; PINHEIRO, L. R. D. Neuromarketing em tempo de crise. South American Development Society Journal, v. 2, n. 5, p. 87-101, 2017.

NASCIMENTO, C. L.; JIMENEZ, G. G.; CAMPOMAR, M. C. A rede social como fonte de informação para o processo de decisão de compra. Future Studies Research Journal, v. 6, n. 2, p. 31-47, 2014.

PASSARELLI, Brasilina. Jovens brasileiros em conectividade contínua: estudos e tendências. Revista Juventude e Políticas Públicas, v. 2, n. EE, p. 1-16, 2020.

REDIVO, C.; GOUVEIA, T. A. O uso do Neuromarketing para decifrar o consumidor. Revista Aproximando, v. 4, n. 5, 2018.

RODRIGUES, G.; BACALTCHUK, B.; DE OLIVEIRA, L. Lendo mentes: estudo sobre o uso do neuromarketing para a compreensão do comportamento do consumidor. A arte de fazer ciência: Problematizar, Pesquisar e Publicar. VIII Mostra de Iniciação Científica IMED, 2014.

SANTOS, T. M. Aplicabilidade do inbound marketing para geração de leads em uma empresa de presentes criativos. Administração-Pedra Branca, 2019.

SAMPAIO, L. et al. Netflix e o Neuromarketing: Primeira incursões. In: Sociedade Brasileira de Estudos Interdisciplinares da Comunicação/ XX Congresso de Ciências da Comunicação na Região Sul-Porto Alegre-RS. Anais [...] Porto Alegre: Intercom, 2019.

SPIGUEL, P. R.; BAGLI, F. de L. Neuromarketing: o uso da ciência a favor do marketing. Toledo, 2013. ETIC - Encontro de Iniciação Científica das Faculdades Integradas Antônio Eufrásio De Toledo, v. 9, n. 9, PR, Toledo, 2013.

VORPAGEL, E. B. Neuromarketing: uma nova forma de entender o consumidor. CAP Accounting and Management, v. 2017, n. 10, p. 38-46, 2016. 